\title{
Preserving fertility in young patients with endometrial cancer: current perspectives
}

This article was published in the following Dove Press journal:

International Journal of Women's Health

29 July 2014

Number of times this article has been viewed

\author{
Eleftheria Kalogera \\ Sean C Dowdy \\ Jamie N Bakkum-Gamez \\ Division of Gynecologic Surgery, \\ Mayo Clinic, Rochester, MN, USA
}

Correspondence: Jamie N Bakkum-Gamez Mayo Clinic, 200 First Street SW, Rochester, Minnesota 55905, USA

Tel +l 5075385867

Fax +I 5072669300

Email bakkum.jamie@mayo.edu
Abstract: Endometrial cancer (EC) is the most common gynecologic malignancy in developed countries and affects predominantly postmenopausal women. It is estimated, however, that $15 \%-25 \%$ of women will be diagnosed before menopause. As more women choose to defer childbearing until later in life, the feasibility and safety of fertility-sparing EC management have been increasingly studied. Definitive treatment of total hysterectomy and bilateral salpingooophorectomy precludes future fertility and may thus be undesirable by women who wish to maintain their reproductive potential. However, the consideration of conservative management carries the oncologic risks of unstaged EC and the risk of missing a synchronous ovarian cancer. It is further complicated by the lack of consensus regarding the initial assessment, treatment, and surveillance. Conservative treatment with progestins has been shown to be a feasible and safe fertility-sparing approach for women with low grade, early stage EC with no myometrial invasion. The two most commonly adopted regimens are medroxyprogesterone acetate at $500-600 \mathrm{mg}$ daily and megestrol acetate at $160 \mathrm{mg}$ daily for a minimum of $6-9$ months, with initial response rates commonly reported between $60 \%$ and $80 \%$ and recurrence rates between $25 \%$ and $40 \%$. Photodynamic therapy and hysteroscopic EC excision have recently been reported as alternative approaches to progestin therapy alone. However, limited efficacy and safety data exist. Live birth rates after progestin therapy have typically been reported around $30 \%$; however, when focusing only on those who do pursue fertility after successful treatment, the live birth rates were found to be higher than $60 \%$. Assisted reproductive technology has been associated with a higher live birth rate compared with spontaneous conception, most likely reflecting the presence of infertility at baseline. Close follow-up is of paramount importance, and definitive treatment after completion of childbearing is advised.

Keywords: early stage endometrial cancer, fertility sparing, preserving fertility, conservative treatment, progestin, levonorgestrel intrauterine device

\section{Introduction}

Endometrial cancer (EC) is the most common gynecologic malignancy in developed countries, with an estimated 142,200 new cases in 2008 and an incidence rate of 12.9 per 100,000 women. ${ }^{1}$ It is the third most common cause of gynecologic cancer death, with a mortality rate of 2.4 per $100,000 .{ }^{1}$ In the US it is estimated that 52,630 women will be diagnosed with EC and 8,590 women will die from the disease in 2014. ${ }^{2}$ Although the majority of women diagnosed with EC are postmenopausal, it is estimated that $15 \%-25 \%$ of women will be diagnosed before menopause; ${ }^{2-8} 10 \%$ will be aged $<45$ years and $4 \%$ aged $<40$ years. ${ }^{3,7}$

The standard initial treatment for EC includes total hysterectomy and bilateral salpingo-oophorectomy (BSO) and/or pelvic and para-aortic lymph node assessment. ${ }^{9}$ 
Younger women tend to be diagnosed with low grade, early stage disease and have excellent prognosis with 5- and 10-year disease-free survival (DFS) of up to $99.2 \%$ and $98 \%$, respectively. ${ }^{10-13}$ Furthermore, prognosis tends to be more favorable in women aged $<45$ years compared with older women, whose 5-year DFS for low grade, early stage disease is only $86 \%$. $^{7,10,11,13}$ Given the excellent oncologic outcomes associated with early stage EC in young women, the importance of improving quality of life and preserving fertility while maintaining excellent DFS has been recognized. This is especially important as an increasing number of women are choosing to defer childbearing until later in life. One out of 12 women is estimated to give birth after age 35 years today, compared with only one out of 100 in $1970 .{ }^{14}$ As such, definitive surgical EC treatment may not be desired by women who have not completed childbearing. Fertility-sparing options for EC management have become increasingly investigated.

Several groups have described the feasibility and safety of fertility-sparing hormone therapy for early stage EC. ${ }^{15-21}$ Despite the fact that hormone treatment of EC was first reported in 1961, a contemporary consensus standardizing conservative management does not exist. Specifically, there are various approaches to the initial assessment of young women with EC; the optimal agent, dosing, and duration of treatment are unclear; and surveillance modalities and frequency after treatment are not standardized. A novel hybrid approach that combines local hysteroscopic excision of the tumor with hormone treatment was recently introduced with encouraging results, yet only limited data are available, further complicating decision making. ${ }^{22-24}$ Nonsurgical EC management is also challenged by the risk of missing an advanced stage EC, as well as the risk of missing an early stage synchronous ovarian cancer (OC). Additionally, the development of EC at a young age may be the herald of Lynch syndrome. Because the pathogenesis is less likely to be primarily related to a hormone imbalance, and hormone therapy may therefore be ineffective, identification of patients with Lynch syndrome is critical. Overall, counseling young women with an EC diagnosis on their options remains complex.

In this review we will present the current data and perspectives on fertility-preserving management of young women with EC. We will particularly focus on contemporary clinical trials and the controversies surrounding conservative management.

\section{Hormone treatment}

\section{Progestin treatment}

\section{Patient selection}

Although the majority of young women diagnosed with EC have early stage disease, there remains a non-negligible risk of disease extending beyond the uterus; the reported incidence of stage III or IV disease ranges from $10.5 \% 5$ to $29.5 \%{ }^{6,7}$ Additionally, there appears to be a higher rate of synchronous OC among young women with EC, ranging from $5 \%$ to $29 \%$, compared with the overall risk of $5 \%$ of synchronous ovarian and endometrial malignancies among all women diagnosed with EC. ${ }^{25-27}$ Specifically, Gitsch et $\mathrm{al}^{6}$ observed a significantly higher incidence of synchronous ovarian malignancies in women aged $<45$ years with EC (29.4\%) compared with their older counterparts (4.6\%), and Walsh et $\mathrm{al}^{25}$ reported that $25 \%$ of young women with EC in their cohort were found to have coexisting OCs. As such, proper patient selection for conservative EC management and thorough pretreatment evaluation are crucial.

Key parameters when assessing women for conservative management include grade of disease, depth of myometrial invasion, and the presence of adnexal masses. Although there is no consensus on the optimal workup, a thorough pretreatment evaluation for these parameters is necessary. Dilation and curettage (D\&C) is recommended to best assess grade, as D\&C appears to correlate better with final posthysterectomy grade compared with office endometrial sampling. ${ }^{28}$ In addition, it has been suggested that D\&C may offer a greater reduction of tumor burden compared with endometrial biopsy. ${ }^{29}$

Although various methods to evaluate myometrial involvement have been studied, including transvaginal ultrasonography and computed tomography (CT), contrastenhanced magnetic resonance imaging (MRI) is most commonly utilized to estimate the depth of myometrial invasion. In a meta-analysis comparing the utility of CT, ultrasonography, and MRI, the range of sensitivity reported by different studies was 40-100\% for CT, 50-100\% for ultrasound, compared to $80-100 \%$ for contrast-enhanced MRI. ${ }^{30}$ Sironi et $\mathrm{al}^{31}$ evaluated the diagnostic performance of MRI in assessing the extent of myometrial involvement in patients with clinical stage I EC. The sensitivity of MRI to determine that the tumor was confined to the endometrium was $57 \%$, with a specificity of $96 \%$. Sensitivity and specificity were both $74 \%$ in determining the presence of superficial myometrial invasion (defined as presence of superficial myometrial $<50 \%$ myometrial invasion). MRI carried a sensitivity of $88 \%$ and a specificity of $85 \%$ to determine deep myometrial invasion (defined as $>50 \%$ myometrial invasion). ${ }^{31}$ In a pooled analysis of prospective studies comparing T2-weighted and contrastenhanced MRI, Wu et al ${ }^{32}$ observed similar sensitivity $(87 \%$ versus $81 \%$, respectively), positive predictive value (64\% versus $65 \%$ ), and negative predictive value ( $84 \%$ versus $85 \%$ ), whereas contrast-enhanced MRI had superior specificity 
(58\% versus $72 \%$ ) when assessing myometrial invasion. Contrast-enhanced MRI may also provide information on lymph node status as well as cervical involvement in EC. ${ }^{33}$ Furthermore, MRI is typically accepted as the next best imaging study following ultrasonography in characterizing an adnexal mass. In a meta-analysis focusing on the performance of different imaging modalities in diagnosing OC, estimated sensitivity was $86 \%-91 \%$ for ultrasonography, $91 \%$ for MRI, and $90 \%$ for CT. However, the diagnostic performance in detecting extrauterine disease spread in EC patients has been reported to be considerably lower; Zerbe et $\mathrm{al}^{34}$ observed a $60 \%$ sensitivity of CT to detect adnexal involvement in EC patients. Given the apparent increased rate of synchronous ovarian malignancies among young women with EC and that pretreatment imaging and cancer antigen 125 are limited in their sensitivity to detect synchronous lesions, with up to $15 \%$ of EC patients with subsequently diagnosed adnexal involvement having normal preoperative imaging, ${ }^{25}$ some gynecologic oncologists perform diagnostic laparoscopy at the time of initial evaluation. ${ }^{35,36}$ However, even this approach is limited, as the presence of occult ovarian malignancy in the setting of intraoperatively benign-appearing ovaries has been reported to vary from $4 \%$ to $25 \%$. ${ }^{6,25,27,37}$

Finally, pretreatment evaluation should include assessment for inherited gynecologic cancer syndromes such as Lynch syndrome. Additionally, it is important that women are counseled that a negative genetic evaluation does not exclude the risk of a synchronous or metachronous ovarian malignancy.

Ideal candidates for conservative management are young women with grade 1, early stage EC with no myometrial invasion who are highly motivated to maintain their reproductive potential and understand and are willing to accept the risks associated with deviation from the standard of care. Although this review will focus on this patient population, it is important to note that there are a few encouraging reports of conservative management of grade 1 EC with superficial myometrial involvement ${ }^{38}$ and grade 2 or $3 \mathrm{EC}$ with no myometrial invasion. ${ }^{16,18,38-43}$ Given the paucity of data, conservatively managing higher grade disease should be considered with caution.

\section{Agents, dosage, and duration of treatment}

There is no consensus regarding the ideal progestin agent, dose, or duration of treatment. The two most common regimens are medroxyprogesterone acetate (MPA) at 500-600 mg daily and megestrol acetate (MA) at $160 \mathrm{mg}$ daily. ${ }^{44,45}$ In a recent systematic review and meta-analysis, Gunderson et $\mathrm{al}^{46}$ reported that within the overall cohort, $49 \%$ received MPA,
25\% MA, and 19\% were treated with a levonorgestrel intrauterine device (LNG-IUD), though no comparison across types of progestin was performed. Evidence supporting the superiority of MPA over MA was recently published by Park et al, ${ }^{45}$ who suggested that although response rates were similar between the two agents, MA was associated with a significantly higher risk of recurrence. Similarly, in a case series of grade $1 \mathrm{EC}$ and complex atypical hyperplasia (CAH) previously published by our group, we observed a higher response rate to MPA compared with MA. ${ }^{15} \mathrm{~A}$ wide range of MA and MPA doses has been reported, ranging from $10 \mathrm{mg}$ to $400 \mathrm{mg}$ daily for MA and from $2.5 \mathrm{mg}$ to $800 \mathrm{mg}$ daily for MPA. ${ }^{44}$ Ushijima et $\mathrm{al}^{47}$ observed better response with MPA at $600 \mathrm{mg}$ compared with $200 \mathrm{mg}$ or $400 \mathrm{mg}$ daily, and other investigative groups have adopted this high-dose MPA regimen with similar outcomes. ${ }^{18,48-53}$ However, similar to other published experiences, ${ }^{21,49,50,54}$ all nine patients in our series treated with MPA received 10-20 mg daily and $88.9 \%$ had durable complete response, defined as complete initial response with no later recurrence. ${ }^{15}$ Eftekhar et al ${ }^{55}$ used an augmentation protocol that included use of MA at a starting dose of $160 \mathrm{mg}$ daily for 3 months, with nonresponders receiving double the dose for an additional one or two 3-month periods, and observed complete response in $86 \%$ of the cohort with a mean treatment duration of 9 months. Although response rates to progestins are substantial, high doses of progestins also carry the risks of side effects and complications, with a higher likelihood of noncompliance. The choice of progestin, dose, and route of administration should be individualized to minimize risks such as thrombophlebitis, weight gain, headaches, sleep disorders, mood and libido changes, and leg cramps. ${ }^{18,56,57}$

An alternative to systemic progestins that may reduce these risks is the LNG-IUD. The LND-IUD has not been as well studied as oral progestins, but complete response rates from $40 \%$ to $100 \%$ have been reported in premenopausal women with well-differentiated, early stage EC. ${ }^{58-60}$ None of these studies reported any specific difficulties with follow-up in the presence of an IUD, reflecting the fact that endometrial biopsy can still be performed with a Pipelle with the IUD in place.

When considering all progestin treatment options, the minimum duration of treatment needed to achieve disease regression appears to be 3 months. ${ }^{20,56,61-63}$ However, the median duration of treatment required for disease regression appears to be 4-6 months. ${ }^{15,20,21,47,51,53,64-68}$ Additionally, as obese and anovulatory patients tend to be more resistant to treatment, longer treatment durations should be considered among them. ${ }^{16,45,69}$ 


\section{Surveillance for response to treatment}

Close surveillance to evaluate treatment response is of paramount importance; however, a single standardized surveillance protocol does not exist. It is important to confirm disease regression from an oncologic standpoint as well as from a reproductive standpoint. Of note, there is not a universally accepted definition of complete disease regression, with some investigators considering the presence of simple hyperplasia and/or complex hyperplasia without atypia in follow-up biopsies as complete regression, while others do not. Although thinning of the endometrial lining on transvaginal ultrasound has been associated with favorable response to treatment, ${ }^{47}$ documentation from tissue diagnosis, via either endometrial curettage or office endometrial biopsy, remains the standard criterion to assess response to treatment. Various intervals of follow-up have been reported, ranging from endometrial sampling every month ${ }^{52,70}$ to every 6-7 months; ; ${ }^{541-75}$ however, a 3-month interval appears to be the most frequent approach. ${ }^{46}$ As 3 months of treatment appears to be the minimum required before disease response is observed, ${ }^{20,56,61-63}$ a first follow-up sampling at 3 months would provide close surveillance while minimizing the frequency of an uncomfortable procedure between treatment initiation and expected response. However, individualization may be required for each patient, given the paucity of data and lack of consensus on surveillance interval.

The duration that each woman's cancer will remain in remission after progestin therapy cannot be predicted, and, as such, women achieving complete disease regression should be counseled to promptly pursue fertility if desired. Given that conditions such as polycystic ovarian syndrome are risk factors for both EC and infertility, it is also reasonable to consider early referral to a reproductive endocrinologist. Women not planning to attempt pregnancy immediately after achieving complete response should be placed on maintenance progestin therapy. Maintenance treatment with low-dose cyclic progestin or an LNG-IUD has been shown to lower the risk of recurrence after complete response among young women with EC undergoing fertility-sparing treatment. ${ }^{45,47,62,76}$ Women with persistence or progression of their disease after 6-9 months of treatment ${ }^{15,21}$ should be counseled about the lower likelihood of response with continuing treatment and the need to consider a more definitive approach.

\section{Follow-up after successful treatment}

Surveillance after successful response to treatment is essential, given the risk of EC recurrence as well as the risk of synchronous OC. Although recurrent EC tends to be confined to the uterus in the majority of fertility preservation cases, there have been reports of extrauterine spread, even in patients with complete response to initial treatment. ${ }^{18,19,77}$ Follow-up surveillance should occur every 3-6 months after complete response and should, as a minimum, include a thorough pelvic examination, endometrial sampling, cancer antigen 125, and imaging, such as transvaginal ultrasound, MRI, and/or CT, to evaluate the adnexa. ${ }^{45,54,62,66,78,79}$ As previously discussed, it is critical to underscore the importance of maintaining the patients on progestational therapy until pregnancy or hysterectomy, as well as between pregnancies.

\section{Oncologic outcomes}

The majority of young women with low grade, early stage EC who desire fertility preservation respond to progestin therapy. The range of response rates published in the literature varies, with some studies reporting response rates between $42 \%$ and $62 \%$ 48,54,60,68 and others reporting higher rates of $78 \%-100 \%{ }^{52,62,65,66,76,80}$ Factors that could account for these differences include 1) variations in treatment duration, as longer treatment durations could result in higher response rates, ${ }^{15,64}$ and 2) differences in definitions of "complete response". Some studies define complete response as no residual disease at follow-up endometrial biopsy, regardless of whether there is disease relapse in a future follow-up biopsy. Other investigators distinguish initial response from durable complete response.

In a meta-analysis of 32 studies published between 1985 and 2011, the estimated pooled disease regression rate (defined by the authors as lack of residual EC or CAH during follow-up endometrial sampling) was $76.2 \%$, with median follow-up ranging from 11 months to 76 months. ${ }^{44}$ In another review of 38 studies from 2004 to 2011, Gunderson et $\mathrm{al}^{46}$ found an initial response rate of $74.6 \%$, with $48.2 \%$ experiencing a durable complete response and $35.4 \%$ of the entire cohort experiencing a recurrence after initial complete response, with median follow-up from 2 months to 138 months. Additionally, $25.4 \%$ of the pooled cohort had persistent/progressive disease. These results are similar to the findings of Ramirez et al, ${ }^{20}$ with an estimated initial response rate of $76 \%$ and an ultimate recurrence rate of $24 \%$ among initial responders, with median follow-up from 0 years to 30 years.

The duration of treatment required to obtain EC resolution ranges from 1 month to 17 months, and the most common estimated median time to response is 4-6 months. ${ }^{15,20,21,47,51,53,64-68}$ Although lack of response 
within 2 months of initiating progestin treatment has been suggested as a sign of lower likelihood of achieving complete response,${ }^{47}$ there is growing evidence that longer treatment with progestins (duration of treatment $>6-12$ months) is feasible and results in higher response rates without altering clinical/oncologic outcome. . $^{15,51,64}$

Although the rate of synchronous OC in women with EC aged $\leq 45$ years has been reported to range from $5 \%$ to $29 \%,{ }^{25}$ in a recent meta-analysis the reported rate was only $3.6 \%$ among women opting for fertility-sparing treatment. As this meta-analysis included cases of $\mathrm{CAH}$, the rate of $3.6 \%$ may be an underestimate of the risk among those diagnosed with EC. ${ }^{44}$ Among reported cases of synchronous and metachronous OC, outcomes appear to be favorable, with long-term DFS and overall survival after $\mathrm{OC}$ diagnosis and treatment. ${ }^{21,66}$ Nevertheless, a missed OC diagnosis or EC metastasis to the ovary in the setting of conservative EC management carries a risk of increased mortality. Thorough evaluation of the adnexae is critical, and, as noted, some surgeons advocate diagnostic laparoscopy prior to initiating progestin therapy to evaluate for extrauterine disease and primary ovarian malignancy. ${ }^{35,36}$

It is important to recognize that conservative treatment, although initially successful in the majority of women, is a temporizing measure. The risk of recurrence after completion of treatment is high, even among women who experience a rapid complete response, as well as among those on maintenance progestin therapy. EC recurrence rates range from $24 \%$ to $40.6 \%$, and although most recurrences occur within the first 3 years of successful conservative therapy, recurrences can occur in as little as 2 months and up to 30 years after treatment. ${ }^{20,44,45,64,81}$ Cumulative recurrence risk has been reported to be $51 \%$ after 3 years and $72 \%$ after 7 years. ${ }^{64}$ Others have reported 5-year recurrence-free survival of $68 \%{ }^{45}$ Nevertheless, most recurrences appear to be confined to the uterus. To date, there have been only seven patients reported in the literature with initial response to progestins who presented with advanced disease at the time of EC recurrence; however, four of them died of their disease. . $8,47,53,77,82-84$ And as the first EC-related death following successful fertility-preserving therapy was reported in January 2004, publication bias may be providing false reassurance. ${ }^{65}$

Standard treatment for recurrent disease after fertilitypreserving treatment is hysterectomy, which precludes future fertility. As some women may still wish to maintain their reproductive potential despite recurrence, repeat fertility-sparing treatment may be considered. However, data supporting repeat progestin therapy in the setting of recurrent EC are even more limited than in the primary setting. ${ }^{16,47,55,64,65,76,85,86}$ In 2013, Park et al ${ }^{85}$ reported on the safety and efficacy of progestin retreatment in a cohort of 33 women with recurrent uterine-confined EC after initial successful progestin treatment. They observed a response rate of $85 \%$ after second-round progestin treatment, with a durable complete response rate of $85 \%$ over a median follow-up of 52 months. All but one patient were disease free at the end of the study (one patient was undergoing the third round of progestin treatment for multirecurrent disease). The few other published studies on outcomes of repeat fertilitysparing treatment have reported similar findings, ${ }^{16,47,55,64,65,86}$ which suggests that progestin retreatment in the setting of initial complete response may be feasible and safe, albeit a temporary approach, for women who decline definitive treatment at the time of uterine-confined $\mathrm{EC}$ recurrence.

Among women who fail to achieve complete response and undergo definitive surgical management, most will have low grade EC on final pathology. ${ }^{45,64}$ Recently, a cohort of 33 patients who failed progestin treatment and underwent hysterectomy was reported: $75.8 \%$ had grade 1 EC confined to the endometrium, $12.1 \%$ had atypical hyperplasia, and $12.1 \%$ had no residual disease. ${ }^{45}$ However, progestin therapy does not preclude development of more aggressive histologies, and higher grade EC may be encountered at the time of hysterectomy. ${ }^{5,53,58,76}$ It has also been reported that up to $13 \%$ of patients undergoing hysterectomy after failed progestin treatment will have higher grade disease. ${ }^{58}$

Few reliable predictors of disease treatment success have been identified. ${ }^{45,50,87}$ Body mass index $\geq 25 \mathrm{~kg} / \mathrm{m}^{2}$ has been found to be associated not only with higher risk of progestin failure but also with higher risk of recurrence after complete response. ${ }^{45}$ This finding underscores the importance of weight reduction in young EC patients desiring conservative management, as their disease is likely hormone dependent. Additional independent predictors of a lower risk of recurrence include successful subsequent pregnancy, use of maintenance progestin therapy, and use of MPA. ${ }^{45}$ Molecular markers may also be able to predict response; the expression of phospho-Akt and phosphatase and tensin homologue within the primary prehormone-treated tumor appears to be associated with a higher risk of post-treatment hysterectomy among women opting for conservative progestin therapy for CAH and grade 1, stage IA EC..$^{50}$ However, these molecular markers are not currently clinically utilized.

\section{Reproductive outcomes}

In a recent review among 280 women conservatively treated for EC, 86 women achieved pregnancy (34.8\%), with 89 
total live births. ${ }^{46}$ Another study reported a pooled live birth rate of $28 \%{ }^{44}$ However, although all women included in these reviews reportedly wished to preserve their reproductive potential, not all attempted pregnancy during the respective study periods. ${ }^{44,46}$

Perhaps the most detailed pregnancy outcomes following progestin therapy were reported by Park et $\mathrm{al}^{88}$ in 2013. Among 141 EC patients with complete response to progestin treatment, half attempted to conceive at a median time of 5 months after treatment completion. Pregnancy and live birth rates were $73 \%$ and $66 \%$, respectively, for those who attempted pregnancy. However, when factoring in those who did not attempt pregnancy, the live birth rate was $26 \%,{ }^{88}$ which is similar to other reports. ${ }^{44}$ Pregnancy rates between $40 \%$ and $50 \%,{ }^{42,52,68,76,79,89}$ or even higher, ${ }^{49,64,90}$ have also been reported.

Although most providers would require complete regression of EC prior to encouraging pregnancy, one prospective study of conservative management of $\mathrm{CAH}$ and low grade, early stage EC allowed women to attempt pregnancy before achieving complete response, as pregnancy itself was considered to be a natural, extremely high-dose progestin therapy. ${ }^{79}$ Although live births occurred in this study, there were also patients with persistent disease or EC relapse after pregnancy requiring definitive treatment. Of note, all patients were alive and free of disease at the end of the study, with a median follow-up of 98 months. Additionally, although the numbers are low, women who required more than 1 year to respond to progestins have had successful full-term pregnancies. ${ }^{64}$ However, it is important to note that there are very few cases of successful pregnancy reported among women undergoing retreatment for EC recurrence after complete initial response. ${ }^{64,76,85,88}$

Cumulative data suggest that assisted reproductive technology (ART) is associated with a higher live birth rate compared with spontaneous conception in young women with EC. Lower spontaneous fertility rates could reflect the presence of EC risk factors that are also associated with infertility, such as obesity, polycystic ovarian syndrome, and chronic anovulation. In a recent systematic review, the live birth rate among women who underwent ART was significantly higher than the rate among the remaining women who were presumed to have attempted pregnancy spontaneously $(39.4 \%$ versus $14.9 \%$, respectively; $P=0.001) .{ }^{44}$ Also, although both EC and $\mathrm{CAH}$ cases were included in this analysis, the pooled live birth rate appeared to be comparable between the two groups (EC: $28 \%$ versus CAH: $26.3 \%$ ). Better estimates of actual pregnancy success rates after ART compared with spontaneous pregnancy attempts are derived from studies including only women who do attempt pregnancy after progestins. In the Park et $\mathrm{al}^{88}$ study, use of ART was associated with significantly higher pregnancy and live birth rates compared with women who attempted spontaneous conception (pregnancy rates: $86.4 \%$ versus $50 \%, P=0.001$; live birth rates: $70.5 \%$ versus $42.3 \%, P=0.020)$. Similar promising outcomes supporting the use of ART in this patient population have also been reported. ${ }^{49,58,62,64,76,89,90}$

Following biopsy-proven complete disease regression, reproductive endocrinologists have used standard in vitro fertilization protocols for ovarian stimulation in the majority of the cases. ${ }^{42,43,74,91-94}$ The safety of fertility drugs in this setting has been questioned, as the association between their use and the risk of EC is unclear. ${ }^{95-98}$ In one study, the use of ART did not increase the risk of recurrence, nor did it influence the DFS. ${ }^{88}$ Additionally, women who achieved pregnancy exhibited a better DFS compared with their counterparts, irrespective of fertility drug use. Collectively, there is growing evidence supporting the safety and feasibility of ART in young EC patients following successful fertility-sparing treatment. ${ }^{64,68,99,100}$ In an effort to decrease the effects of estrogen exposure to the endometrium, Juretzka et al ${ }^{101}$ used a PG-IUD during ovarian stimulation. Toward this direction, Azim and Oktay ${ }^{102}$ suggested in 2007 an ovarian stimulation protocol based on the use of letrozole, an aromatase inhibitor, in conjunction with gonadotropins, which was associated with lower estrogen levels compared with standard stimulation cycles as well as good reproductive outcomes. The authors suggested the use of letrozole not only on the basis of its ovulation induction effect and their prior experience with a similar ovulation induction protocol in breast cancer patients but also for its relative safety in EC patients. ${ }^{103-106}$

In summary, early referral to reproductive endocrinology in the setting of fertility-sparing EC treatment should be considered in order to maximize the likelihood of a live birth and minimize the time between diagnosis and definitive EC treatment.

\section{Definitive treatment}

Women failing conservative treatment due to either disease progression or lack of regression should undergo definitive treatment consisting of hysterectomy, BSO, and/or lymphadenectomy. Definitive surgery should be considered if no evidence of disease regression is observed within 6-9 months of treatment initiation, as the likelihood of success with further treatment is low. Even if conservative treatment is initially successful with biopsy-proven regres- 
sion of disease, $40.6 \%$ of responders will recur, even despite the use of maintenance therapy. ${ }^{44,45}$ Therefore, once women who have been successfully treated with progestins have completed childbearing, they should undergo definitive surgery. Also, given the limited data on the safety of progestin retreatment in the setting of recurrent disease, ${ }^{16,47,55,64,65,76,85,86}$ those who experience recurrence should also undergo hysterectomy, BSO, and/or lymphadenectomy. Women who decline definitive treatment after appropriate counseling should be carefully followed.

\section{Ovarian preservation in the setting of surgical treatment}

The risks and benefits of ovarian preservation in young women with low grade, early stage EC undergoing definitive treatment require individualization. ${ }^{107-110}$ The safety of ovarian preservation in young women with EC has been studied via the National Cancer Institute's Surveillance, Epidemiology, and End Results (SEER) database. ${ }^{108}$ Among 3,269 women aged $\leq 45$ years, $12 \%$ had ovarian preservation. In a multivariate Cox model, ovarian preservation had no effect on cancer-specific or overall survival. Additionally, in a retrospective cohort of women aged $\leq 45$ years representing all stages of EC, although BSO appeared to lead to better DFS, especially in stage I disease, it did not appear to improve overall survival. ${ }^{110}$ Similarly, in 2013, Sun et al ${ }^{109}$ found that ovarian preservation did not negatively impact overall survival in a cohort of 166 young Chinese women with EC. Nonetheless, it is important to recognize that ovarian preservation carries a potentially life-threatening risk of missing occult synchronous ovarian malignancy or metastatic disease, $5,6,25,107,111$ even if the ovaries appear benign during intraoperative inspection; in fact, among all synchronous cases of EC and OC, approximately 15\% may have macroscopically normal-appearing ovaries at the time of surgery. ${ }^{25}$

Ovarian preservation does, however, afford an opportunity for fertility preservation in the setting of hysterectomy, given the potential for future oocyte retrieval and surrogacy, both of which are emerging concepts in the fertility preservation literature. ${ }^{112-114}$

\section{Nonhormone conservative treatment}

Photodynamic therapy (PDT) has recently been introduced as a novel treatment modality for early stage $\mathrm{EC}^{115}$ and has previously been reported as treatment for esophageal, endobronchial, bladder, vulvar, vaginal, and cervical cancers and precancerous lesions. ${ }^{116-123}$ PDT uses a nontoxic light-sensitive compound (photosensitizing agent), which upon selective exposure to light of a specific wavelength produces active oxygen species that are toxic to surrounding cancer cells. ${ }^{124}$ The selection of the specific photosensitizing agent and corresponding wavelength depends on the distance that the light needs to travel in order to target the cancer. In 2013, Choi et $\mathrm{l}^{115}$ published the outcomes of a cohort of 16 young EC patients pursuing fertility-sparing management who were treated with PDT. Among them, PDT was used as the primary treatment in eleven patients and as secondary treatment for recurrence after failed hormone therapy in five patients. The initial response rate was 75\% (12/16) and recurrence rate was 33\% (four/12). Of the four patients who recurred, two elected to undergo definitive surgical treatment and two continued PDT with complete response (one patient after one additional PDT course and one after two courses). The pregnancy rate was $57 \%$. The only adverse effect that was observed was mild facial angioedema in $25 \%$ of the patients, which was managed conservatively. Recognizing that this is a single report, the authors concluded that PDT could potentially be an effective conservative treatment method for highly motivated women who wish to pursue fertility-sparing treatment. ${ }^{115}$

\section{Fertility-sparing surgical treatment}

A few investigators have suggested hysteroscopic surgical excision of the lesion followed by progestin as an alternative conservative management approach in young women with EC. ${ }^{22-24}$ In 2009, Mazzon et $\mathrm{al}^{24}$ published a case series of six patients with stage IA EC who underwent conservative resectoscopic treatment using a three-step technique first reported in 2005. First, the tumor was removed; second, the endometrium adjacent to the tumor was removed; and, third, the myometrium underlying the tumor was resected. ${ }^{23}$ If final pathology confirmed grade 1 EC with no myometrial invasion, patients were subsequently treated with progestins for 6 months. There were no complications related to the hysteroscopic surgery, and all women had complete regression of disease after 3 months' treatment. Importantly, there were no recurrences after a median follow-up of 50.5 months. Four out of the six patients had successful pregnancies without the use of ART, at a median time of 24 months after treatment completion, and two were actively attempting pregnancy when the study was published. ${ }^{23}$ In 2011, Laurelli et al ${ }^{22}$ published a study of 14 stage IA EC patients using a similar approach of combined operative hysteroscopy and hormone therapy. Similar to Mazzon et al, ${ }^{24}$ no perioperative complications were observed, and all patients had initial response to treatment. 
Only one woman experienced disease recurrence 5 months after hysteroscopic resection, and she was subsequently managed with hysterectomy. At a median follow-up of 40 months, all patients were alive with no evidence of disease. Of the three patients who attempted to conceive, ART was not utilized and there was one live birth. Although these preliminary reports are promising, larger studies are necessary to further assess safety and efficacy of combined hysteroscopic resection and progestin therapy as an option for fertility-preserving management of young women with EC.

\section{Conclusion}

Although fertility-sparing management of EC is not the current standard of care for young women with EC, it may be considered for those patients with low grade, apparent early stage disease who wish to maintain their reproductive potential. Candidates should be carefully selected using strict selection criteria (grade 1, early stage EC with no myometrial invasion; highly motivated to maintain their reproductive potential; fully comprehend and are willing to accept the risks associated with deviation from the standard of care; and agreeable to a close follow-up schedule) and thoroughly counseled on the oncologic risks associated with unstaged EC as well as the risk of synchronous OC. Pretreatment assessment of the extent of disease to rule out myometrial invasion and/or extrauterine spread is essential, with MRI currently being the most sensitive imaging modality to detect myometrial invasion while having a diagnostic ability to detect adnexal involvement comparable with transvaginal ultrasonography. Although the ideal treatment regimen is yet to be determined, recent data suggest that MA may be associated with a higher risk of recurrence compared with MPA. The LNG-IUD is increasingly emerging as an alternative to oral progestins; however, more prospective studies with longer follow-up periods are warranted before definitive conclusions can be drawn on its efficacy and safety in the conservative treatment of EC. The majority of patients will respond after 4-6 months of progestin treatment. However, time to complete resolution of EC can vary from as soon as 3 months to more than 1 year, with data suggesting that a trial of 1 year of treatment with close follow-up is reasonable before abandoning progestins. Ultimately, a considerable subset of those experiencing complete response who will attempt to become pregnant will have live births. It is also important that patients are counseled early about the higher live birth rates associated with ART and the potential need for this technology. Despite highly durable complete response rates of $50 \%-75 \%$, the risk of recurrence remains a reality even for those with complete initial response. Close follow-up is essential, and definitive treatment after completion of childbearing is recommended. The risk of localized EC recurrence should not discourage physicians from offering fertility preservation options to highly motivated women. Alternative approaches to progestins alone include PDT and hysteroscopic EC excision followed by progestin treatment, and these have had encouraging results; however, larger studies are needed as the current data are limited. The majority of data to date are from retrospective observational studies. However, large prospective trials on conservative management of early stage $\mathrm{EC}$ and/or $\mathrm{CAH}$ with progestins, LNG-IUD, or a combination of both, are emerging (http:// www.clinicaltrials.gov: NCT00788671, NCT01074892, NCT00483327, and NCT01594879). Further assessment of oncologic and reproductive outcomes through high-quality prospective clinical trials will help guide standardization of treatment, surveillance, and overall management of young women with EC who desire fertility preservation.

\section{Disclosure}

The authors report no conflicts of interest in this report.

\section{References}

1. Jemal A, Bray F, Center MM, Ferlay J, Ward E, Forman D. Global cancer statistics. CA Cancer J Clin. 2011;61:69-90.

2. Siegel R, Ma J, Zou Z, Jemal A. Cancer statistics, 2014. CA Cancer J Clin. 2014;64:9-29.

3. Creasman WT, Odicino F, Maisonneuve P, et al. Carcinoma of the corpus uteri. J Epidemiol Biostat. 2001;6:47-86.

4. Barakat RR, Bundy BN, Spirtos NM, Bell J, Mannel RS. Randomized double-blind trial of estrogen replacement therapy versus placebo in stage I or II endometrial cancer: a Gynecologic Oncology Group Study. J Clin Oncol. 2006;24:587-592.

5. Duska LR, Garrett A, Rueda BR, Haas J, Chang Y, Fuller AF. Endometrial cancer in women 40 years old or younger. Gynecol Oncol. 2001;83:388-393.

6. Gitsch G, Hanzal E, Jensen D, Hacker NF. Endometrial cancer in premenopausal women 45 years and younger. Obstet Gynecol. 1995;85:504-508.

7. Lee NK, Cheung MK, Shin JY, et al. Prognostic factors for uterine cancer in reproductive-aged women. Obstet Gynecol. 2007;109:655-662.

8. Tran BN, Connell PP, Waggoner S, Rotmensch J, Mundt AJ. Characteristics and outcome of endometrial carcinoma patients age 45 years and younger. Am J Clin Oncol. 2000;23:476-480.

9. Pecorelli S. Revised FIGO staging for carcinoma of the vulva, cervix, and endometrium. Int J Gynaecol Obstet. 2009;105:103-104.

10. Crissman JD, Azoury RS, Barnes AE, Schellhas HF. Endometrial carcinoma in women 40 years of age or younger. Obstet Gynecol. 1981;57:699-704.

11. Gallup DG, Stock RJ. Adenocarcinoma of the endometrium in women 40 years of age or younger. Obstet Gynecol. 1984;64:417-420.

12. Lajer H, Elnegaard S, Christensen RD, Ortoft G, Schledermann DE, Mogensen O. Survival after stage IA endometrial cancer; can follow-up be altered? A prospective nationwide Danish survey. Acta Obstet Gynecol Scand. 2012;91:976-982. 
13. Silverberg SG, Makowski EL, Roche WD. Endometrial carcinoma in women under 40 years of age: comparison of cases in oral contraceptive users and non-users. Cancer. 1977;39:592-598.

14. Matthews TJ, Hamilton BE. Delayed childbearing: more women are having their first child later in life. NCHS Data Brief. 2009:1-8.

15. Bakkum-Gamez J, Kalogera E, Keeney G, Mariani A, Podratz K, Dowdy S. Conservative management of atypical hyperplasia and grade I endometrial carcinoma: Review of the literature and presentation of a series. J Gynecol Surg. 2012;28:262-269.

16. Gotlieb WH, Beiner ME, Shalmon B, et al. Outcome of fertility-sparing treatment with progestins in young patients with endometrial cancer. Obstet Gynecol. 2003;102:718-725.

17. Jobo T, Imai M, Kawaguchi M, Kenmochi M, Kuramoto H. Successful conservative treatment of endometrial carcinoma permitting subsequent pregnancy: report of two cases. Eur J Gynaecol Oncol. 2000;21:119-122.

18. Kaku T, Yoshikawa H, Tsuda H, et al. Conservative therapy for adenocarcinoma and atypical endometrial hyperplasia of the endometrium in young women: central pathologic review and treatment outcome. Cancer Lett. 2001;167:39-48.

19. Kim YB, Holschneider CH, Ghosh K, Nieberg RK, Montz FJ. Progestin alone as primary treatment of endometrial carcinoma in premenopausal women. Report of seven cases and review of the literature. Cancer. 1997;79:320-327.

20. Ramirez PT, Frumovitz M, Bodurka DC, Sun CC, Levenback C. Hormonal therapy for the management of grade 1 endometrial adenocarcinoma: a literature review. Gynecol Oncol. 2004;95:133-138.

21. Randall TC, Kurman RJ. Progestin treatment of atypical hyperplasia and well-differentiated carcinoma of the endometrium in women under age 40. Obstet Gynecol. 1997;90:434-440.

22. Laurelli G, Di Vagno G, Scaffa C, Losito S, Del Giudice M, Greggi S. Conservative treatment of early endometrial cancer: preliminary results of a pilot study. Gynecol Oncol. 2011;120:43-46.

23. Mazzon I, Corrado G, Masciullo V, Morricone D, Ferrandina G, Scambia G. Conservative surgical management of stage IA endometrial carcinoma for fertility preservation. Fertil Steril. 2010;93:1286-1289.

24. Mazzon I, Corrado G, Morricone D, Scambia G. Reproductive preservation for treatment of stage IA endometrial cancer in a young woman: hysteroscopic resection. Int J Gynecol Cancer. 2005;15:974-978.

25. Walsh C, Holschneider C, Hoang Y, Tieu K, Karlan B, Cass I. Coexisting ovarian malignancy in young women with endometrial cancer. Obstet Gynecol. 2005;106:693-699.

26. Creasman WT, Morrow CP, Bundy BN, Homesley HD, Graham JE, Heller PB. Surgical pathologic spread patterns of endometrial cancer A Gynecologic Oncology Group Study. Cancer. 1987;60:2035-2041.

27. Evans-Metcalf ER, Brooks SE, Reale FR, Baker SP. Profile of women 45 years of age and younger with endometrial cancer. Obstet Gynecol. 1998;91:349-354.

28. Leitao MM Jr, Kehoe S, Barakat RR, et al. Comparison of D\&C and office endometrial biopsy accuracy in patients with FIGO grade 1 endometrial adenocarcinoma. Gynecol Oncol. 2009;113:105-108.

29. Daniel AG, Peters WA 3rd. Accuracy of office and operating room curettage in the grading of endometrial carcinoma. Obstet Gynecol. 1988;71:612-614.

30. Kinkel K, Kaji Y, Yu KK, et al. Radiologic staging in patients with endometrial cancer: a meta-analysis. Radiology. 1999;212: 711-718.

31. Sironi S, Taccagni G, Garancini P, Belloni C, DelMaschio A. Myometrial invasion by endometrial carcinoma: assessment by MR imaging. AJR Am J Roentgenol. 1992;158:565-569.

32. Wu LM, Xu JR, Gu HY, Hua J, Haacke EM, Hu J. Predictive value of T2-weighted imaging and contrast-enhanced MR imaging in assessing myometrial invasion in endometrial cancer: a pooled analysis of prospective studies. Eur Radiol. 2013;23:435-449.

33. Manfredi R, Mirk P, Maresca G, et al. Local-regional staging of endometrial carcinoma: role of MR imaging in surgical planning. Radiology. 2004;231:372-378.
34. Zerbe MJ, Bristow R, Grumbine FC, Montz FJ. Inability of preoperative computed tomography scans to accurately predict the extent of myometrial invasion and extracorporal spread in endometrial cancer. Gynecol Oncol. 2000;78:67-70.

35. Morice P, Fourchotte V, Sideris L, Gariel C, Duvillard P, Castaigne D. A need for laparoscopic evaluation of patients with endometrial carcinoma selected for conservative treatment. Gynecol Oncol. 2005;96: 245-248.

36. Navarria I, Usel M, Rapiti E, et al. Young patients with endometrial cancer: how many could be eligible for fertility-sparing treatment? Gynecol Oncol. 2009;114:448-451.

37. Soliman PT, Slomovitz BM, Broaddus RR, et al. Synchronous primary cancers of the endometrium and ovary: a single institution review of 84 cases. Gynecol Oncol. 2004;94:456-462.

38. Park JY, Kim DY, Kim TJ, et al. Hormonal therapy for women with stage IA endometrial cancer of all grades. Obstet Gynecol. 2013;122:7-14.

39. Brown AJ, Westin SN, Broaddus RR, Schmeler K. Progestin intrauterine device in an adolescent with grade 2 endometrial cancer. Obstet Gynecol. 2012;119:423-426.

40. Imai M, Jobo T, Sato R, Kawaguchi M, Kuramoto H. Medroxyprogesterone acetate therapy for patients with adenocarcinoma of the endometrium who wish to preserve the uterus-usefulness and limitations. Eur $J$ Gynaecol Oncol. 2001;22:217-220.

41. Koskas M, Yazbeck C, Walker F, et al. Fertility-sparing management of grade 2 and 3 endometrial adenocarcinomas. Anticancer Res. 2011;31:3047-3049.

42. Sardi J, Anchezar Henry JP, Paniceres G, Gomez Rueda N, Vighi S. Primary hormonal treatment for early endometrial carcinoma. Eur J Gynaecol Oncol. 1998;19:565-568.

43. Zuckerman B, Lavie O, Neuman M, et al. Endometrial carcinoma stage I - grade II. Conservative treatment followed by a healthy twin pregnancy. Int J Gynecol Cancer. 1998;8:172-174.

44. Gallos ID, Yap J, Rajkhowa M, Luesley DM, Coomarasamy A, Gupta JK. Regression, relapse, and live birth rates with fertility-sparing therapy for endometrial cancer and atypical complex endometrial hyperplasia: a systematic review and metaanalysis. Am J Obstet Gynecol. 2012;207:266

45. Park JY, Kim DY, Kim JH, et al. Long-term oncologic outcomes after fertility-sparing management using oral progestin for young women with endometrial cancer (KGOG. 2002). Eur J Cancer. 2013;49:868-874.

46. Gunderson CC, Fader AN, Carson KA, Bristow RE. Oncologic and reproductive outcomes with progestin therapy in women with endometrial hyperplasia and grade 1 adenocarcinoma: a systematic review. Gynecol Oncol. 2012;125:477-482.

47. Ushijima K, Yahata H, Yoshikawa H, et al. Multicenter phase II study of fertility-sparing treatment with medroxyprogesterone acetate for endometrial carcinoma and atypical hyperplasia in young women. J Clin Oncol. 2007;25:2798-2803.

48. Hahn HS, Yoon SG, Hong JS, et al. Conservative treatment with progestin and pregnancy outcomes in endometrial cancer. Int J Gynecol Cancer. 2009;19:1068-1073.

49. Han AR, Kwon YS, Kim DY, et al. Pregnancy outcomes using assisted reproductive technology after fertility-preserving therapy in patients with endometrial adenocarcinoma or atypical complex hyperplasia. Int J Gynecol Cancer. 2009;19: 147-151.

50. Minaguchi T, Nakagawa S, Takazawa Y, et al. Combined phospho-Akt and PTEN expressions associated with post-treatment hysterectomy after conservative progestin therapy in complex atypical hyperplasia and stage Ia, G1 adenocarcinoma of the endometrium. Cancer Lett. 2007;248:112-122.

51. Yahata T, Fujita K, Aoki Y, Tanaka K. Long-term conservative therapy for endometrial adenocarcinoma in young women. Hum Reprod. 2006;21:1070-1075.

52. Niwa K, Tagami K, Lian Z, Onogi K, Mori H, Tamaya T. Outcome of fertility-preserving treatment in young women with endometrial carcinomas. BJOG. 2005;112:317-320. 
53. Ota T, Yoshida M, Kimura M, Kinoshita K. Clinicopathologic study of uterine endometrial carcinoma in young women aged 40 years and younger. Int J Gynecol Cancer. 2005;15:657-662.

54. Cade TJ, Quinn MA, Rome RM, Neesham D. Progestogen treatment options for early endometrial cancer. BJOG. 2010;117:879-884.

55. Eftekhar Z, Izadi-Mood N, Yarandi F, Shojaei H, Rezaei Z, Mohagheghi S. Efficacy of megestrol acetate (megace) in the treatment of patients with early endometrial adenocarcinoma: our experiences with 21 patients. Int J Gynecol Cancer. 2009;19:249-252.

56. Montz FJ, Bristow RE, Bovicelli A, Tomacruz R, Kurman RJ. Intrauterine progesterone treatment of early endometrial cancer. Am J Obstet Gynecol. 2002;186:651-657.

57. Farhi DC, Nosanchuk J, Silverberg SG. Endometrial adenocarcinoma in women under 25 years of age. Obstet Gynecol. 1986;68:741-745.

58. Kudesia R, Singer T, Caputo TA, et al. Reproductive and oncologic outcomes after progestin therapy for endometrial complex atypical hyperplasia or carcinoma. Am J Obstet Gynecol. 2014;210(3):255.

59. Mentrikoski MJ, Shah AA, Hanley KZ, Atkins KA. Assessing endometrial hyperplasia and carcinoma treated with progestin therapy. Am J Clin Pathol. 2012;138:524-534.

60. Wheeler DT, Bristow RE, Kurman RJ. Histologic alterations in endometrial hyperplasia and well-differentiated carcinoma treated with progestins. Am J Surg Pathol. 2007;31:988-998.

61. Jadoul P, Donnez J. Conservative treatment may be beneficial for young women with atypical endometrial hyperplasia or endometrial adenocarcinoma. Fertil Steril. 2003;80:1315-1324.

62. Mao Y, Wan X, Chen Y, Lv W, Xie X. Outcomes of conservative therapy for young women with early endometrial adenocarcinoma. Fertil Steril. 2010;93:283-285.

63. Shen ZQ, Zhu HT, Lin JF. Reverse of progestin-resistant atypical endometrial hyperplasia by metformin and oral contraceptives. Obstet Gynecol. 2008;112:465-467.

64. Perri T, Korach J, Gotlieb WH, et al. Prolonged conservative treatment of endometrial cancer patients: more than 1 pregnancy can be achieved. Int J Gynecol Cancer. 2011;21:72-78.

65. Chiva de Agustin L, Lapuente Sastre F, Corraliza Galan V, et al. Conservative management of patients with early endometrial carcinoma: a systematic review. Clin Transl Oncol. 2008;10:155-162.

66. Yamazawa K, Hirai M, Fujito A, et al. Fertility-preserving treatment with progestin, and pathological criteria to predict responses, in young women with endometrial cancer. Hum Reprod. 2007;22: 1953-1958

67. Bovicelli A, D’Andrilli G, Giordano A, De Iaco P. Conservative treatment of early endometrial cancer. J Cell Physiol. 2013;228:1154-1158.

68. Chiva L, Lapuente F, Gonzalez-Cortijo L, et al. Sparing fertility in young patients with endometrial cancer. Gynecol Oncol. 2008;111: S101-S104.

69. Penner KR, Dorigo O, Aoyama C, et al. Predictors of resolution of complex atypical hyperplasia or grade 1 endometrial adenocarcinoma in premenopausal women treated with progestin therapy. Gynecol Oncol. 2012;124:542-548.

70. Wu HM, Lai CH, Huang HY, Wang HS, Soong YK. A successful live twin birth by in vitro fertilization after conservative treatment of recurrent endometrial cancer. Chang Gung Med J. 2008;31:102-106.

71. Demirol A, Bahce M, Ayhan A, Gurgan T. Pregnancy following intracytoplasmic sperm injection and preimplantation genetic diagnosis after the conservative management of endometrial cancer. Reprod Biomed Online. 2005;10:770-773.

72. Kresowik J, Ryan GL, Van Voorhis BJ. Progression of atypical endometrial hyperplasia to adenocarcinoma despite intrauterine progesterone treatment with the levonorgestrel-releasing intrauterine system. Obstet Gynecol. 2008;111:547-549.

73. Qi X, Zhao W, Duan Y, Li Y. Successful pregnancy following insertion of a levonorgestrel-releasing intrauterine system in two infertile patients with complex atypical endometrial hyperplasia. Gynecol Obstet Invest. 2008;65:266-268.
74. Yarali H, Bozdag G, Aksu T, Ayhan A. A successful pregnancy after intracytoplasmic sperm injection and embryo transfer in a patient with endometrial cancer who was treated conservatively. Fertil Steril. 2004;81:214-216.

75. Yasuda M, Matsui N, Kajiwara H, et al. Malignant transformation of atypical endometrial hyperplasia after progesterone therapy showing germ-cell tumor-like differentiation. Pathol Int. 2004;54: 451-456.

76. Park H, Seok JM, Yoon BS, et al. Effectiveness of high-dose progestin and long-term outcomes in young women with early-stage, welldifferentiated endometrioid adenocarcinoma of uterine endometrium. Arch Gynecol Obstet. 2012;285: 473-478.

77. Wang CB, Wang CJ, Huang HJ, et al. Fertility-preserving treatment in young patients with endometrial adenocarcinoma. Cancer. 2002;94:2192-2198.

78. Gotlieb WH. Fertility preserving treatments for endometrial cancer: the unanswered questions. Gynecol Oncol. 2013;129:1-2.

79. Signorelli M, Caspani G, Bonazzi C, Chiappa V, Perego P, Mangioni C. Fertility-sparing treatment in young women with endometrial cancer or atypical complex hyperplasia: a prospective single-institution experience of 21 cases. BJOG. 2009;116:114-118.

80. Koskas M, Azria E, Walker F, Luton D, Madelenat P, Yazbeck C. Progestin treatment of atypical hyperplasia and well-differentiated adenocarcinoma of the endometrium to preserve fertility. Anticancer Res. 2012;32:1037-1043.

81. Hubbs JL, Saig RM, Abaid LN, Bae-Jump VL, Gehrig PA. Systemic and local hormone therapy for endometrial hyperplasia and early adenocarcinoma. Obstet Gynecol. 2013;121:1172-1180.

82. Cormio G, Martino R, Loizzi V, Resta L, Selvaggi L. A rare case of choroidal metastasis presented after conservative management of endometrial cancer. Int J Gynecol Cancer. 2006;16:2044-2048.

83. Ferrandina G, Zannoni GF, Gallotta V, Foti E, Mancuso S, Scambia G. Progression of conservatively treated endometrial carcinoma after full term pregnancy: a case report. Gynecol Oncol. 2005;99:215-217.

84. Greenblatt RB, Gambrell RD Jr, Stoddard LD. The protective role of progesterone in the prevention of endometrial cancer. Pathol Res Pract. 1982;174:297-318.

85. Park JY, Lee SH, Seong SJ, et al. Progestin re-treatment in patients with recurrent endometrial adenocarcinoma after successful fertility-sparing management using progestin. Gynecol Oncol. 2013;129:7-11.

86. Yu M, Yang JX, Wu M, Lang JH, Huo Z, Shen K. Fertility-preserving treatment in young women with well-differentiated endometrial carcinoma and severe atypical hyperplasia of endometrium. Fertil Steril. 2009;92:2122-2124.

87. Kamoi S, Ohaki Y, Mori O, Kurose K, Fukunaga M, Takeshita T. Serial histologic observation of endometrial adenocarcinoma treated with high-dose progestin until complete disappearance of carcinomatous foci - review of more than 25 biopsies from five patients. Int J Gynecol Cancer. 2008;18:1305-1314.

88. Park JY, Seong SJ, Kim TJ, et al. Pregnancy outcomes after fertilitysparing management in young women with early endometrial cancer. Obstet Gynecol. 2013;121:136-142.

89. Shirali E, Yarandi F, Eftekhar Z, Shojaei H, Khazaeipour Z. Pregnancy outcome in patients with stage 1a endometrial adenocarcinoma, who conservatively treated with megestrol acetate. Arch Gynecol Obstet. 2012;285(3):791-795.

90. Chao AS, Chao A, Wang CJ, Lai CH, Wang HS. Obstetric outcomes of pregnancy after conservative treatment of endometrial cancer: case series and literature review. Taiwan J Obstet Gynecol. 2011;50:62-66.

91. Lowe MP, Bender D, Sood AK, Davis W, Syrop CH, Sorosky JI. Two successful pregnancies after conservative treatment of endometrial cancer and assisted reproduction. Fertil Steril. 2002;77:188-189.

92. Nakao Y, Nomiyama M, Kojima K, Matsumoto Y, Yamasaki F, Iwasaka T. Successful pregnancies in 2 infertile patients with endometrial adenocarcinoma. Gynecol Obstet Invest. 2004;58: $68-71$. 
93. Ogawa S, Koike T, Shibahara H, et al. Assisted reproductive technologies in conjunction with conservatively treated endometrial adenocarcinoma. A case report. Gynecol Obstet Invest. 2001;51: 214-216.

94. Pinto AB, Gopal M, Herzog TJ, Pfeifer JD, Williams DB. Successful in vitro fertilization pregnancy after conservative management of endometrial cancer. Fertil Steril. 2001;76:826-829.

95. Althuis MD, Moghissi KS, Westhoff CL, et al. Uterine cancer after use of clomiphene citrate to induce ovulation. Am J Epidemiol. 2005; 161:607-615.

96. Dor J, Lerner-Geva L, Rabinovici J, et al. Cancer incidence in a cohort of infertile women who underwent in vitro fertilization. Fertil Steril 2002;77:324-237.

97. Jensen A, Sharif H, Kjaer SK. Use of fertility drugs and risk of uterine cancer: results from a large Danish population-based cohort study. Am J Epidemiol. 2009;170:1408-1414.

98. Silva Idos S, Wark PA, McCormack VA, et al. Ovulation-stimulation drugs and cancer risks: a long-term follow-up of a British cohort. Br J Cancer. 2009;100:1824-1831.

99. Elizur SE, Beiner ME, Korach J, Weiser A, Ben-Baruch G, Dor J. Outcome of in vitro fertilization treatment in infertile women conservatively treated for endometrial adenocarcinoma. Fertil Steril. 2007;88:1562-1567.

100. Ichinose M, Fujimoto A, Osuga Y, et al. The influence of infertility treatment on the prognosis of endometrial cancer and atypical complex endometrial hyperplasia. Int J Gynecol Cancer. 2013;23: 288-293.

101. Juretzka MM, O’Hanlan KA, Katz SL, El-Danasouri I, Westphal LM Embryo cryopreservation after diagnosis of stage IIB endometria cancer and subsequent pregnancy in a gestational carrier. Fertil Steril. $2005 ; 83: 1041$.

102. Azim A, Oktay K. Letrozole for ovulation induction and fertility preservation by embryo cryopreservation in young women with endometrial carcinoma. Fertil Steril. 2007;88:657-664.

103. Berstein L, Maximov S, Gershfeld E, et al. Neoadjuvant therapy of endometrial cancer with the aromatase inhibitor letrozole: endocrine and clinical effects. Eur J Obstet Gynecol Reprod Biol. 2002;105: 161-165.

104. Morsi HM, Leers MP, Nap M, Bjorklund VV, El Kabarity H, Jaeger W. Apoptosis and anti-apoptosis in oestrogen-receptor negative endometrial cancer cells in response to anastrozole, 4-hydroxytamoxifen and medroxyprogesterone acetate. Eur J Cancer. 2000;36 Suppl 4:112-113.

105. Sasano H, Kaga K, Sato S, Yajima A, Nagura H, Harada N. Aromatase cytochrome P450 gene expression in endometrial carcinoma. $\mathrm{Br} J$ Cancer. 1996;74:1541-1544.

106. Sasano H, Sato S, Ito K, et al. Effects of aromatase inhibitors on the pathobiology of the human breast, endometrial and ovarian carcinoma. Endocr Relat Cancer. 1999;6:197-204.

107. Lee TS, Jung JY, Kim JW, et al. Feasibility of ovarian preservation in patients with early stage endometrial carcinoma. Gynecol Oncol. 2007;104:52-57.
108. Wright JD, Buck AM, Shah M, Burke WM, Schiff PB, Herzog TJ. Safety of ovarian preservation in premenopausal women with endometrial cancer. J Clin Oncol. 2009;27:1214-1219.

109. Sun C, Chen G, Yang Z, et al. Safety of ovarian preservation in young patients with early-stage endometrial cancer: a retrospective study and meta-analysis. Fertil Steril. 2013;100:782-787.

110. Richter CE, Qian B, Martel M, et al. Ovarian preservation and staging in reproductive-age endometrial cancer patients. Gynecol Oncol. 2009;114:99-104.

111. ShamshirsazAA, Withiam-Leitch M, Odunsi K, Baker T, Frederick PJ, Lele S. Young patients with endometrial carcinoma selected for conservative treatment: a need for vigilance for synchronous ovarian carcinomas, case report and literature review. Gynecol Oncol. 2007; 104:757-760.

112. Bernardini L, Asch RH. Spontaneous resolution of ectopic pregnancy in a surrogate after oocyte donation and frozen embryo transfer. Hum Reprod. 1996;11:2785-2788.

113. Lavery S, Ng C, Kyrgiou M, Farthing A. Gestational surrogacy after intra-operative oocyte collection in a hysterectomised woman diagnosed with endometrial cancer. BJOG. 2011;118:1669-1671.

114. Caserta D, Ralli E, Matteucci E, Marci R, Moscarini M. Fertility preservation in female cancer patients: an emerging challenge for physicians. Panminerva Med. 2014;56:85-95.

115. Choi MC, Jung SG, Park H, Cho YH, Lee C, Kim SJ. Fertility preservation via photodynamic therapy in young patients with earlystage uterine endometrial cancer: a long-term follow-up study. Int $J$ Gynecol Cancer. 2013;23:698-704.

116. Foroulis CN, Thorpe JA. Photodynamic therapy (PDT) in Barrett's esophagus with dysplasia or early cancer. Eur J Cardiothorac Surg. 2006;29:30-34.

117. Hopper C. Photodynamic therapy: a clinical reality in the treatment of cancer. Lancet Oncol. 2000;1:212-219.

118. Triesscheijn M, Baas P, Schellens JH, Stewart FA. Photodynamic therapy in oncology. Oncologist. 2006;11:1034-1044.

119. Hillemanns P, Wang X, Staehle S, Michels W, Dannecker C. Evaluation of different treatment modalities for vulvar intraepithelial neoplasia (VIN): $\mathrm{CO}(2)$ laser vaporization, photodynamic therapy, excision and vulvectomy. Gynecol Oncol. 2006;100:271-275.

120. Krimbacher E, Zeimet AG, Marth C, Kostron H. Photodynamic therapy for recurrent gynecologic malignancy: a report on 4 cases. Arch Gynecol Obstet. 1999;262:193-197.

121. Lele SB, Piver MS, Mang TS, Dougherty TJ, Tomczak MJ. Photodynamic therapy in gynecologic malignancies. Gynecol Oncol. 1989;34:350-352.

122. Rettenmaier MA, Berman ML, DiSaia PJ, Burns RG, Berns MW. Photoradiation therapy of gynecologic malignancies. Gynecol Oncol. 1984;17:200-206.

123. Yamaguchi S, Tsuda $\mathrm{H}$, Takemori M, et al. Photodynamic therapy for cervical intraepithelial neoplasia. Oncology. 2005;69:110-116.

124. National Cancer Institute. Photodynamic Therapy for Cancer. Available from: http://www.cancer.gov/cancertopics/factsheet/Therapy/ photodynamic. Accessed July 16, 2014.
International Journal of Women's Health

\section{Publish your work in this journal}

The International Journal of Women's Health is an international, peerreviewed open-access journal publishing original research, reports, editorials, reviews and commentaries on all aspects of women's healthcare including gynecology, obstetrics, and breast cancer. The manuscript management system is completely online and includes

\section{Dovepress}

a very quick and fair peer-review system, which is all easy to use. Visit http://www.dovepress.com/testimonials.php to read real quotes from published authors. 